\title{
PENGARUH MENGUNYAH PERMEN KARET TERHADAP RASA HAUS PADA PASIEN HEMODIALISA
}

\author{
Andreas Rantepadang ${ }^{1}$ Gracela Gwendolin Taebenu ${ }^{2}$ \\ 1. Dosen, Fakultas Keperawatan, Universitas Klabat, Airmadidi, Manado, 95371, Indonesia
}

2. Mahasiswa, Fakultas Keperawatan, Universitas Klabat, Airmadidi, Manado, 95371, Indonesia

E-mail: rantepadang@unklab.ac.id, getaebenu9@gmail.com

\begin{abstract}
Hemodialysis patients feel thirsty that cause discomfort and affect the quality of life. One of the methods used to reduce thirsty is to chew gum (xylitol). This study aimed to determine the effect of chewing gum on thirst in hemodialysis patients at Manado Adventist Hospital. Design of this research used quasi-experimental with a pre and posttest nonequivalent control group approach. The sampling method used was purposive sampling. The research sample of 30 respondents was divided into 15 respondents for the treatment group and 15 respondents for the control group. Result: The average thirsty before chewing gum in the intervention group (24.40) which indicated being in severe thirsty, after being given an intervention of gum for 2 weeks in the intervention group, the patients' thirsty decreased to (11.47) being in mild thirsty. Whereas first day control group (23.20) which was in severe thirst, and thirst after 2 weeks the control group (23.07) remained in severe thirst. The result of the mann whitney $u$-test statistical test found $p$ value $0.000<0.05$ where there was a significant effect of chewing gum on thirst in hemodialysis patients. Recommendation: For hemodialysis patients can use gum as an alternative therapy to reduce thirsty.
\end{abstract}

Keywords: chewing gum, thirsty, hemodialysis

\begin{abstract}
Abstrak
Pasien hemodialisa mengalami rasa haus yang menyebabkan ketidaknyamanan dan mempengaruhi kualitas hidup, mengunyah permen karet (xylitol) merupakan salah satu intervensi yang dapat digunakan untuk mengurangi rasa haus. Penelitian ini bertujuan untuk mengetahui pengaruh mengunyah permen karet terhadap rasa haus pada pasien hemodialisa di Rumah Sakit Advent Manado. Desain penelitian quasi-eksperimental dengan pendekatan pre and posttest nonequivalent control group design. Metode sampling adalah purposive sampling. Sampel penelitian 30 responden dibagi atas 15 responden kelompok perlakuan dan 15 responden kelompok kontrol. Hasil penelitian: rata-rata rasa haus sebelum mengunyah permen karet pada kelompok intervensi $(24,40)$ berada pada rasa haus berat, setelah diberikan intevensi permen karet selama 2 minggu rasa haus pasien menurun menjadi $(11,47)$ rasa haus ringan. Sedangkan pada kelompok kontrol rasa haus pada hari pertama $(23,20)$ berada pada rasa haus berat, setelah 2 minggu, tetap berada pada haus berat $(23,07)$. Hasil uji statistik mann whitney u-test didapati nilai $p$ value $0,000<0,05$ di mana terdapat pengaruh yang signifikan mengunyah permen karet terhadap rasa haus pada pasien hemodialisa. Rekomendasi: Bagi pasien yang menjalani hemodialisa dapat menggunakan permen karet sebagai terapi alternatif untuk mengurangi rasa haus.
\end{abstract}

Kata kunci: mengunyah permen karet, rasa haus, hemodialisa 


\section{Pendahuluan}

Gagal ginjal kronik atau chronic kidney disease adalah penyimpangan progresif, fungsi ginjal yang tidak dapat pulih, dimana kemampuan tubuh mempertahankan keseimbangan metabolik, cairan dan elektrolit, yang mengakibatkan uremia (Smeltzer \& Bare, 2010). Kondisi ini disebabkan oleh glomerulonefritis kronis, pielonefritis, hipertensi tak terkontrol, lesi herediter, kelainan vaskular, obstruksi saluran perkemihan, diabetes, dan infeksi. Dewasa ini, penyakit ginjal kronik merupakan salah satu penyakit yang prevalensinya terus meningkat (Baughman \& Hackley, 2012).

Menurut World Health Organization (WHO) jumlah penderita gagal ginjal pada tahun 2013 telah meningkat 50\% dari tahun 2012. Berdasarkan Center for Disease Control and Prevention (CDC) pada tahun 2010, lebih dari 20 juta atau $10 \%$ dari jumlah orang dewasa di Amerika Serikat mengidap penyakit gagal ginjal kronik,sedangkan di Indonesia populasi berusia $\geq 15$ tahun yang terdiagnosis gagal ginjal kronik sebesar $0,2 \%$ dari jumlah penduduk (Riskesdas, 2013). Dimana 98\% menjalani terapi Hemodialisa (Indonesian Renal Registry, 2016).

Terapi hemodialisis merupakan salah satu cara bagi penderita gagal ginjal kronis untuk bisa bertahan hidup. Dengan tujuan untuk membuang produk sisa metabolisme dari peredaran darah manusia berupa air, natrium, kalium, hidrogen, urea, dan kreatinin, melalui membran semipermeable atau disebut dialiser. Penderita gagal ginjal kronis menjadikan hemodialisis sebagai rutinitas dan pasien yang menjalani hemodialisa harus mempertahankan pembatasan asupan cairan untuk mengontrol dan membatasi jumlah asupan cairan sehingga tercapai keseimbangan cairan tubuh agar tidak terjadi kelebihan cairan (Harsismanto, Rifai dan Tuti, 2008; Price \& Wilson, 2013).

Kelebihan cairan pada pasien yang menjalani hemodialisis dapat menyebabkan penambahan berat badan, edema, peningkatan tekanan darah, sesak nafas, dan gangguan jantung yang menurunkan kualitas hidup pasien, maka dari itu pembatasan cairan harus dilakukan pada pasien hemodialisa walaupun pasien akan mengalami keluhan xerostomia dan rasa haus (Guyton \& Hall, 2016).

Rasa haus adalah respon fisiologis dari dalam tubuh manusia berupa keinginan untuk memenuhi kebutuhan cairan dalam tubuh. Diperkirakan 68 - 86\% dari pasien yang menjalani hemodialisis mengungkapkan pengalaman rasa haus atau mulut kering, yang menyebabkan ketidaknyamanan dan penderitaan pada pasien hemodialisis sehingga dapat mempengaruhi kualitas hidup (Fan \& Zhang, 2013). Ada beberapa cara yang dilakukan untuk merawat mulut kering dan mengurangi rasa haus pada pasien yang menjalani hemodialisa adalah mengulum es batu (Arfany, Armiyati, \& 
Kusuma, 2015), berkumur dengan air dingin (Fransisca, 2013), mengulum frozen grapes (Dewi, Nurchayati, \& Jumaini, 2018), dan mengunyah permen karet (xylitol) (Ariani, Yasa, \& Arisusana, 2014) .

Permen karet xylitol merupakan permen yang mengandung pemanis buatan yang digunakan sebagai bahan pengganti gula yang sama manisnya dengan sukrosa. Kegiatan mengunyah permen karet rendah gula dua butir \pm 10 menit dengan $3 \mathrm{x} / \mathrm{hari}$ selama 2 minggu akan menimbulkan rangsangan mekanis dan kimiawi yang dapat menggerakkan reflek saliva dengan menstimulasi reseptor yang dipantau oleh nervus trigeminal $(\mathrm{V})$ dan nervus fasial (VII) sebagai pengecap. Stimulasi saraf simpatis akan mempercepat sekresi pada semua kelenjar saliva dalam jumlah banyak yang dapat menurunkan sensasi rasa haus yang muncul (Ganong, 2008; Said \& Mohammed, 2013) selain itu permen karet xylitol dapat dibawah kemana-mana serta cara mengkonsumsi yang praktis jika dibandingkan dengan mengulum es batu (Arfany, Armiyati \& Kusuma, 2015). Berkumur dengan air dingin (Fransisca, 2013)

Berdasarkan hasil penelitian yang dilakukan oleh Ariani, Putra, dan Arisusana pada tahun 2014 dengan 20 responden, terdapat pengaruh yang signifikan mengunyah permen karet terhadap rasa haus. Dalam penelitian ini juga mencantumkan bahwa semakin banyak mengunyah permen karet maka rasa haus pada pasien hemodialisa berkurang. Sedangkan pada penelitian yang dilakukan Lastriyanti pada tahun 2014, tidak ada pengaruh mengunyah permen karet terhadap rasa haus karena penelitian ini peneliti hanya memberikan empat buah permen karet dengan durasi lima menit. Maka dari itu peneliti mengadakan penelitian mengenai "Pengaruh mengunyah permen karet terhadap rasa haus pada pasien hemodialisa".

\section{Metode}

Desain penelitian dalam penelitian ini adalah quasi-eksperimental menggunakan pendekatan pre and posttest non equivalent control group design, Cara pembagian kelompok intervensi dan kelompok kontrol yaitu dengan mengurutkan nama-nama pasien yang termasuk dalam kriteria inklusi, kemudian menentukan yang nomor urut genap dijadikan kelompok intervensi dan nomor urut ganjil dijadikan kelompok kontrol. Populasi dalam penelitian ini adalah 55 responden yang menderita gagal ginjal kronik yang menjalani hemodialisa. Sampel yang diambil oleh peneliti adalah 30 responden menggunakan teknik purposive sampling, dengan kriteria inklusi responden yang didiagnosa penyakit ginjal kronis baik pria maupun wanita ( $\geq 18$ tahun) yang sedang menjalani hemodialisa, dengan kondisi pasien stabil, berat kering stabil, mampu berbahasa Indonesia dan bersedia menandatangani Informed consent sedangkan kriteria ekslusi adalah pasien yang menderita diabetes mellitus, penyakit jantung 
iskemik, penyakit autoimun, mempunyai keganasan di rongga mulut, penurunan kesadaran, menolak mengunyah permen karet.

Responden dibagi menjadi dua kelompok yaitu kelompok intervensi dan kontrol, dimana dilakukan pengukuran rasa haus pre-test dengan kuesioner Thirst distres scale yang terdiri dari 6 penyataan, system skoring skala likert yaitu: sangat tidak setuju 1, tidak setuju 2, netral 3, setuju 4, dan sangat setuju 5. Rentang skor 6-30 kemudian dikelompokkan menjadi tiga kategori (1) haus ringan 6-13, (2) haus sedang 14-21, (3) haus berat 22-30 (Kara, 2013; Said \& Mohammed, 2013). Setelah hasil pengukuran rasa haus terkumpul, peneliti memberikan dua butir permen karet xylitol pada kelompok intervensi untuk dikunyah selama +10 menit, $3 x$ /hari selama 2 minggu dan tidak boleh ditelan, peneliti membawah pulang ke rumah permen karet untuk dikonsumsi. Setelah dua minggu peneliti melakukan pengukuran pengukuran rasa haus posttest baik pada intervensi maupun kontrol.

Prinsip etik dalam penelitian yang diterapkan adalah anonymity dimana peneliti tidak mencantumkan nama tapi menulis inisial pada lembar kuesioner, Beneficience dimana peneliti menjelaskan tentang manfaat dari mengunyah permen karet adalah mengurangi rasa haus, yang dapat menguranggi pasien untuk mengkonsumsi air minum. Justice prinsip ini peneliti terapkan dimana kelompok kontrol diberikan intervensi yang sama dengan kelompok intervensi hanya waktu pemberiannya setelah peneliti mengukur post-test.

\section{Hasil dan Pembahasan}

Tabel 1. Rata-rata Rasa Haus Sebelum dan Sesudah Mengunyah Permen Karet Pada elompok perlakuan.

\begin{tabular}{llll}
\hline & & $\begin{array}{l}\text { Std. } \\
\text { deviation }\end{array}$ & Mean \\
\hline Intervensi & $\begin{array}{l}\text { Rasa haus } \\
\text { pretest } \\
\text { Rasa haus } \\
\text { posttest }\end{array}$ & 2,558 & 24,40 \\
& 1,302 & 11,47 \\
\hline
\end{tabular}

Berdasarkan tabel 1 menunjukkan bahwa rata-rata rasa haus sebelum mengunyah permen karetpada kelompok intervensi 24,40 yang artinya berada pada rasa haus berat. Hasil penelitian ini sejalan dengan Smeltzer dan Bare (2010) mengatakan bahwa faktor yang mempengaruhi timbulnya rasa haus karena adanya pembatasan cairan, peningkatan konsentrasi plasma, penurunan volume darah, membran mukosa dan mulut yang kering, angiotensin II, kehilangan kalium, dan faktor-faktor psikologis. Menurut Fan dan Zhang (2013) ada 68-86\% dari pasien yang menjalani hemodialisis mengungkapkan pengalaman rasa haus dan mulut kering, yang dapat mempengaruhi kualitas hidup dan menyebabkan ketidaknyaman dan penderitaan pada pasien hemodialisis.

Setelah diberikan intervensi terapi mengunyah permen karet selama 2 minggu rata-rata rasa haus pasien menurun menjadi 11,47 yang berada pada rasa haus ringan. Hasil penelitian ini sejalan dengan penelitian Said dan 
Mohammed (2013) bahwa mengunyah permen karet sebagai cara mengatasi rasa haus telah dibuktikan pada penelitian dengan memberikan permen karet yang rasa mentol yaitu 6 butir per hari selama 2 minggu yang melibatkan 65 pasien gagal ginjal kronis yang telah melakukan terapi hemodialisa telah menunjukkan penurunan gejala rasa haus dari skor 29,9 menjadi 28,1 yang dimana hasilnya adalah cukup sering haus.

Tabel 2. Rata-rata Rasa Haus Pada Kelompok Kontrol.

\begin{tabular}{llll}
\hline & & $\begin{array}{l}\text { Std. } \\
\text { deviation }\end{array}$ & Mean \\
\hline Control & $\begin{array}{l}\text { Rasa haus } \\
\text { pretest } \\
\text { Rasa haus } \\
\text { posttest }\end{array}$ & 2,007 & 23,20 \\
\hline
\end{tabular}

Berdasarkan tabel 2 menunjukkan bahwa rata-rata rasa haus sebelum pada kelompok kontrol 23,20 yang artinya berada pada rasa haus berat. Pada kelompok kontrol tidak diberikan terapi permen karet sehingga hasil post test rasa haus 23,07 tetap berada pada rasa haus berat. Hasil penelitian ini sejalan dengan penelitian Ariani, Yasa dan Arisusana (2014) bahwa tidak terjadi perubahan rasa haus yang signifikan pada kelompok kontrol dengan 10 responden, nilai ratarata rasa haus pretest 33,00 dan posttest 32,4 yang dimana hasilnya adalah sangat sering haus. Hasil ini menunjukkan bahwa tidak terjadi perubahan nilai rasa haus diakibatkan oleh penurunan sekresi saliva yang terjadi karena faktor pembatasan cairan dan peningkatan kadar urea dalam darah yang menyebabkan munculnya sensasi rasa mulut kering dan rasa haus.

Tabel 3. Uji statistic Mann Whitney U-test untuk Pengaruh Mengunyah Permen Karet Terhadap Rasa Haus

\begin{tabular}{lc}
\hline & P Value \\
\hline $\begin{array}{l}\text { Mengunyah } \\
\text { karet }\end{array}$ & permen \\
Rasa haus & 0.000 \\
\hline
\end{tabular}

Berdasarkan tabel 3 didapati nilai $p$ value $0,000<0,05$, maka ada pengaruh yang signifikan mengunyah permen karet terhadap rasa haus pada pasien hemodialisa. Menurut Ganong (2008) bahwa peningkatan sekresi saliva yang terjadi sebagai hasil dari berbagai rangsangan, yaitu rangsangan mekanik, rangsangan neuronal dan rangsangan kimiawi. Rangsangan mekanik yaitu pengunyahan permen karet yang terjadi dari proses mastikasi, rangsangan neuronal dihantarkan oleh sistem saraf otonom, baik simpatis dan parasimpatis. Rangsangan kimia berupa kandungan rasa manis dari permen karet telah terurai dalam mulut sehingga menyebabkan berkurangnya sensasi mulut kering dan rasa haus.

Hasil penelitian ini sejalan dengan penelitian Ariani, Yasa dan Arisusana (2014) yang mengatakan ada pengaruh yang signifikan mengunyah permen karet xylitol terhadap rasa haus pada pasien chronic kidney disease dengan terapi hemodialisa di ruang hemodialisa BRSU Tabanan dengan nilai signifikan $p=0,000<0,05$. 


\section{Kesimpulan}

Berdasarkan hasil dari penelitian yang telah dilakukan, peneliti mengambil kesimpulan bahwa: Rasa haus sebelum mengunyah permen karet kelompok perlakuan pada pasien hemodialisa berada dalam kategori rasa haus berat. Setelah diberikan intervensi mengunyah permen karet selama 2 minggu, maka terjadi penurunan rasa haus yang berada pada haus ringan. Rasa haus sebelum kelompok kontrol pada pasien hemodialisa berada dalam kategori haus berat. Pada kelompok kontrol, pasien hemodialisa tidak diberikan intervensi mengunyah permen karet hanya mendapat standar perawatan sehari-hari, sehingga tidak terjadi penurunan rasa haus yang tetap berada pada haus berat. Ada pengaruh yang signifikan mengunyah permen karet terhadap rasa haus pada pasien hemodialisa.

\section{Rekomendasi}

Bagi Institusi Rumah Sakit, Penelitian ini dapat digunakan perawat dalam melakukan tindakan mandiri dengan cara edukasi kepada pasien yang menjalani hemodialisa untuk manajemen rasa haus dengan cara mengunyah permen karet xylitol untuk mencegah terjadinya kelebihan cairan. Bagi Institusi Pendidikan, Hasil penelitian ini dapat digunakan sebagai sumber informasi matakuliah keperawatan hemodialisa dan genitourinari, yang dimana mengunyah permen karet xylitol dapat mengatasi rasa haus pada pasien hemodialisa, dan Bagi peneliti selanjutnya, direkomendasikan dapat menambahkan variabel berupa jenis kelamin dan umur supaya dapat mengetahui manakah jenis kelamin atau umur berapakah yang baik untuk mendapat terapi permen karet xylitol.

\section{Daftar Pustaka}

Arfany, N. W., Armiyati, Y., \& Kusuma, M. B. (2014). Efektifitas mengunyah permen karet rendah gula dan mengulum es batu terhadap penurunan rasa haus pada pasien penyakit ginjal kronis yang menjalani hemodialisis di RSUD Tugurejo Semarang.Jurnal Keperawatan dan kebidanan (JIKK). 2-9.

Ariani, N. P., Yasa, D. G., \&Arisusana, M. (2014). Pengaruh mengunyah permen karet xylitol terhadap rasahaus pada pasien CKD dengan terapi hemodialisa. Jurnal Keperawatan. 2-11.

Baughman, D. C., \& Hackley, J. C. (2012). Keperawatan medikal-bedah buku saku dari Brunner \& Suddarth. Jakarta: EGC.

Center for Disease Control and Prevention. (2010) National chronic kidney disease fact sheet 2010. diakses 11 Oktober 2017.

Diakses dari:http://www.cdc.gov/diabetes/ pubs/factsheets/kidney.html.

Dewi, A., Nurchayati, S., \& Jumaini, J. (2018). Perbedaan efektifitas mengunyah permen karet rendah gula dan mengulum grapeice cube terhadap rasa haus pada pasien gagal ginjal kronis yang menjalani 
hemodialisis. Jurnal Online Mahasiswa (JOM) Bidang Ilmu Keperawatan, 5, 304-312.

Fan, W., \& Zhang, Q. (2013). Study on the clinical significance and related factors of thirst and xerostomia in maintenance hemodialysis patients.

Kidney and Blood Pressure Research, 37: 464474.doi:10.1159/000355717.

Fransisca, K. (2013). Dialife: berat interdialisis. from buletin informasi kesehatan ginjal.Diakses dari:http://www.burungmanyar.nl/ wp-content/uploads/2013/08/ edisi-juli-agustus-2013.pdf

Ganong, W. F. (2008). Buku ajar fisiologi kedokteran ed. 22. Jakarta: EGC.

Guyton, A. C., \& Hall, J. E. (2016). Guyton and hall textbook of medical phsyology ed 33. Philadelphia:elseiver.

Harsismanto, H., Rifai, Tuti. A, (2008) Pelaksanaan pembatasan asupan cairan dan natrium pada pasien penyakit ginjal kronis yang menjalani hemodialisa di RSUD DR. M Yunus Bengkulu. Jurnal Keperawatan Muhammadiyah Bengkulu. 2-8

Indonesian Renal Registry. (2016) Laporan indonesian renal registry ke-9.Diakses dari:http://www.indonesia renalregistry.org/data/INDONESI AN RENAL REGISTRY 2016.pdf
Price, S. A., \& Wilson, L. M. (2013).

Patofisiologi : Konsep klinis proses - proses penyakit. Jakarta: EGC.

Riskesdas. (2013). Riset kesehatan dasar.Jakarta: badan penelitian dan pengembangan kesehatan kementrian kesehatan RI.Diakses dari:http://www.depkes.go.id/reso urces/download/general/hasilriskes das2013.pdf

Kara, B. (2013). Validity and reliability of the Turkish Version of the thirst distress. Asian Nursing Research7, 212-218.

Said, H., \& Mohammed, H. (2013). Effect of chewing gum on xerostomia, thirst and interdialytic weight gain in patients on hemodialysis, Life Science Journal, 10, 1767-1776.

Smeltzer, S., \& Bare, B. G. (2010). Brunner and suddarth's texbook of medical surgical (12 ed.). Philadelphia: Wolter kluwer health/Lipincott. 